\title{
Bur open Semen quality of fertile Japanese men: a cross-sectional population-based study of 792 men
}

To cite: Iwamoto T, Nozawa S, Yoshiike M, et al. Semen quality of fertile Japanese men: a crosssectional population-based study of 792 men. BMJ Open 2013;3:e002223.

doi:10.1136/bmjopen-2012002223

- Prepublication history for this paper are available online. To view these files please visit the journal online (http://dx.doi.org/10.1136/ bmjopen-2012-002223).

Received 13 October 2012 Revised 15 December 2012 Accepted 18 December 2012

This final article is available for use under the terms of the Creative Commons Attribution Non-Commercial 2.0 Licence; see http://bmjopen.bmj.com

For numbered affiliations see end of article.

\section{Correspondence to}

Professor Teruaki Iwamoto; t4iwa@iuhw.ac.jp

\section{ABSTRACT}

Objectives: To establish a base line for future studies on temporal trends, to describe potential geographical differences in semen quality and reference values for studies of men from the general population.

Design: Cross-sectional study of fertile men from four areas in Japan. Inclusion criteria were: age 20-45 years at the time of invitation, and both the man and his mother had to be born in Japan. Additionally, the current pregnancy of the female partner had to be achieved by normal sexual relations without any fertility treatment.

Setting: Four Japanese study centres at urban areas located in Sapporo, Osaka, Kanazawa and Fukuoka.

Participants: 792 men, median age 31.4 years, included from 1999 to 2002.

Outcome measures: Semen volume, sperm concentration, total sperm count, sperm motility and sperm morphology.

Results: Semen volumes, percentages of motile spermatozoa and morphologically normal spermatozoa differed slightly between the four groups, whereas no differences in sperm concentrations or total sperm counts were found. In total, $1.2 \%$ of men had a sperm concentration below 5 million $/ \mathrm{ml}, 2.1 \%$ below 10 million/ml, 3.5\% below 15 million/ml and $16.3 \%$ below 40 million/ml. For morphology, $14.7 \%$ had less than $5 \%$ normal spermatozoa. Reproductive hormone levels varied significantly, however, only little from a biological point of view.

Conclusions: This is the first cross-sectional study on semen quality covering fertile men from the major regions of Japan. It showed that semen quality of fertile Japanese men is comparable to that of the best in European regions. The results may serve as reference values for studies of men from the general population.

\section{INTRODUCTION}

Trends in semen quality have been intensively discussed since the meta-analysis by Carlsen $e t \quad a l^{1}$ provided evidence for a

\section{ARTICLE SUMMARY}

Article focus

- During the recent 20 years, several international studies on semen quality in fertile human populations have been published. However, only a single Japanese study of men from the Tokyo metropolitan area has been carried out. These men had relatively low sperm counts.

- Semen quality of fertile men from four other areas in Japan were investigated in order to elucidate potential geographical differences in semen quality and to provide a baseline for future studies on temporal trends and reference values for studies of men from the general population.

Key messages

- This is the first cross-sectional study on semen quality covering fertile men from the major regions of Japan.

- Only minor regional differences were detected between men from the four investigated regions.

- Only $3.5 \%$ had sperm concentrations below the current WHO reference level of 15 million/ml.

- Semen quality varied, but overall it was comparable to that of men from European regions with the best semen quality.

Strengths and limitations of this study

- Large prospective study of semen quality among fertile Japanese men.

- Standardised inclusion criteria and investigation procedures.

- Lack of influence of ethnicity and genetic background on semen quality.

- Limitation is the relatively low participation rate, that is, common to all semen studies.

possible decline over a 50-year period. Retrospective analyses of laboratory semen records indicated deterioration in many but not all study centres: a decrease in semen quality has been reported from different regions including Belgium, ${ }^{2}$ Canada, ${ }^{3}$ 
China, ${ }^{4}$ Finland, ${ }^{5}$ France, ${ }^{6}$ Greece, ${ }^{7}$ Italy, ${ }^{8}$ Norway, ${ }^{9}$ Scotland, ${ }^{10}$ the $\mathrm{USA}^{11}{ }^{12}$ and the $\mathrm{UK}^{13}$; no change has been reported from regions including China, ${ }^{14}$ Denmark, ${ }^{15}$ Finland, ${ }^{16}{ }^{17}$ France, ${ }^{18}$ Israel $^{19}$ and the USA. $^{20}$ In addition, these publications pointed to regional differences in semen quality, which now have been corroborated by several prospectively designed and quality controlled studies. ${ }^{12}{ }^{21-23}$ A recent prospective study showed a declining trend in semen quality in Finland since $1997,{ }^{23}$ although previous retrospective analyses showed no change. ${ }^{17}$

Most of the previously published cross-sectional semen studies originated from Europe or the USA. ${ }^{12} 2122$ Some studies involved young men from the general population as study subjects, whereas others investigated partners of pregnant women (ie fertile men). To our knowledge, there has only been one study of fertile Japanese men that allowed for a comparison between European and Japanese results. ${ }^{24}$ In the study from Kawasaki adjacent to Tokyo in the central part of Japan, the participants had similar semen quality to Danish men who had the lowest sperm counts when men from Denmark, France, Scotland and Finland were compared ${ }^{24}$ in a joint study. ${ }^{21}$

To further characterise the semen quality of Japanese fertile men, we therefore undertook cross-sectional studies of fertile men from four cities in Japan. These studies followed the same protocol as that used in the previous study. ${ }^{21}{ }^{24}$ Our aim was to establish a baseline for future studies on temporal trends, to describe potential geographical differences in semen quality, and reference values for studies of men from the general population in Japan.

\section{METHODS}

The investigation of male partners of pregnant women took place in four study centres placed in the urological units of the university hospitals in Sapporo, Osaka, Kanazawa and Fukuoka, which are geographically different provinces in Japan. The investigation procedures described below were the same as those of the previously published Japanese study ${ }^{24}$ and European studies, ${ }^{21}{ }^{22}$ except for the assessment of semen volume.

\section{Study population}

When pregnant women attended the antenatal care clinics located in urban areas during the gestational weeks $8-12$, they were approached by study nurses who invited the husbands of the women to participate in the semen quality study. The inclusion criteria for the men were as follows: age $20-45$ years at the time of invitation, residence in the local area surrounding the clinic at which he was recruited, and both the man and his mother had to be born and live in Japan. In addition, the current pregnancy of the female partner had to be achieved by normal sexual relations and not as a result of fertility treatment. Cryptorchidism, orchitis, epididymitis, genital tract surgery (including varicocelectomy), chemotherapy, radiotherapy or chronic illness, previous treatment for infertility or reduced fertility, unwanted pregnancy or prolonged time to pregnancy were not criteria for exclusion. Characteristics of the study populations are given in table 1 . The inclusion period in each centre was May 2000 to January 2002 in Sapporo, March 1999 to February 2002 in Osaka, January 1999 to October 2001 in Kanazawa and October 1999 to April 2001 in Fukuoka. A total of 6846 fertile men were invited and 792 participated. Participation rates were $18.8 \%(206 / 1096)$ for the men in Sapporo, 8.8\% (250/ 2844) in Osaka, 16\% (233/1455) in Kanazawa and 7.1\% $(103 / 1451)$ in Fukuoka. According to the time to pregnancy data that was available from 523 couples, except for those from Sapporo, the pregnancy had been conceived in $87.4 \%$ in less than or equal to 12 months.

\section{Questionnaires}

Both the men and their pregnant partners completed a questionnaire in Japanese. The questionnaire included information on age and previous or current diseases including known history of fertility. The original questionnaire that had been used in the European studies ${ }^{21}$ had been translated into Japanese in advance and backtranslated to English to control for translation errors.

\section{Physical examination}

Physical examination of the men was performed by urologists at each centre on the day the man delivered the questionnaire and his semen sample. Testes disposition, varicocele and Tanner stages of pubic hair were evaluated with the men in the standing position. For assessment of testis size, all examiners used the same type of wooden orchidometer (Pharmacia \& Upjohn, Copenhagen, Denmark).

\section{Semen samples}

The participants provided their semen samples by masturbation in a room close to the laboratory. In the laboratory, the samples were kept at $37^{\circ} \mathrm{C}$ until analysis. The men had been asked to abstain from ejaculation for at least $48 \mathrm{~h}$ prior to participation in the study. The actual abstinence period was calculated as the time between the current and previous ejaculations based on self-reported information from the men. Semen volume was assessed by aspirating the entire sample into a graduated $5 \mathrm{ml}$ syringe (TERUMO, Tokyo, Japan) after liquefying at $37^{\circ} \mathrm{C}$. Sperm motility was assessed on $10 \mu \mathrm{l}$ of well-mixed semen placed on a clean glass slide, covered with a $22 \times 22 \mathrm{~mm}$ coverslip, and then examined at a total magnification of 400 times on the heating stage at $37^{\circ} \mathrm{C}$ of a microscope. The sperm were classified as either motile (WHO motility classes A, B or C) or immotile (class $\mathrm{D}$ ), in order to record the proportion of motile sperm. ${ }^{25}$ The motility assessment was repeated on a second $10 \mu \mathrm{l}$ aliquot of semen, and the average value was calculated for the samples. For the assessment of sperm concentration, the samples were diluted in a 
Table 1 Physical appearance and self-reported information of fertile men from four cities in Japan

\begin{tabular}{|c|c|c|c|c|c|c|c|c|c|c|c|}
\hline & \multicolumn{2}{|c|}{$\begin{array}{l}\text { Entire study population } \\
(n=792)\end{array}$} & \multicolumn{2}{|c|}{ Sapporo (n=206) } & \multicolumn{2}{|c|}{ Osaka $(n=250)$} & \multicolumn{2}{|c|}{ Kanazawa $(n=233)$} & \multicolumn{3}{|c|}{ Fukuoka (n=103) } \\
\hline & Mean (SD) & $\begin{array}{l}\text { Median } \\
(5-95)\end{array}$ & $\begin{array}{l}\text { Mean } \\
\text { (SD) }\end{array}$ & $\begin{array}{l}\text { Median } \\
(5-95)\end{array}$ & $\begin{array}{l}\text { Mean } \\
\text { (SD) }\end{array}$ & $\begin{array}{l}\text { Median } \\
(5-95)\end{array}$ & $\begin{array}{l}\text { Mean } \\
\text { (SD) }\end{array}$ & $\begin{array}{l}\text { Median } \\
(5-95)\end{array}$ & $\begin{array}{l}\text { Mean } \\
\text { (SD) }\end{array}$ & $\begin{array}{l}\text { Median } \\
(5-95)\end{array}$ & p Values \\
\hline Height (cm) & $172(6)$ & $172(163-180)$ & $171(5)$ & $171(162-180)$ & $172(6)$ & $172(162-182)$ & $172(5)$ & $172(163-180)$ & $172(5)$ & $171(165-180)$ & $0.6^{*}$ \\
\hline Weight (kg) & $69(10)$ & $68(55-85)$ & $68(10)$ & 67 (54-87) & $69(10)$ & $68(55-85)$ & 68 (10) & $67(55-85)$ & 69 (10) & $67(55-85)$ & $0.6^{*}$ \\
\hline BMI $\left(\mathrm{kg} / \mathrm{m}^{2}\right)$ & $23(3)$ & 23 (19-29) & $23(3)$ & $23(19-30)$ & $23(3)$ & $23(20-28)$ & $23(3)$ & $23(19-28)$ & $23(3)$ & 23 (19-29) & $0.6^{*}$ \\
\hline $\begin{array}{l}\text { Mean of left and right } \\
\text { size }(\mathrm{ml}) \dagger\end{array}$ & $20(4)$ & $20(15-26)$ & $19(3)$ & $19(15-26)$ & $20(4)$ & $20(14-26)$ & $21(4)$ & $21(15-27)$ & $19(3)$ & $19(16-24)$ & $0.0001^{\star}$ \\
\hline Age (years) $\ddagger$ & $31.7(5.0)$ & $\begin{array}{l}31.4 \\
(24.0-40.3)\end{array}$ & $30.6(5.0)$ & $\begin{array}{l}30.0 \\
(22.0-39.0)\end{array}$ & $32.9(4.7)$ & $\begin{array}{l}32.5 \\
(25.3-41.7)\end{array}$ & $30.9(5.1)$ & $\begin{array}{l}30.6 \\
(24.1-39.2)\end{array}$ & $32.6(4.7)$ & $\begin{array}{l}32.5 \\
(25.9-39.3)\end{array}$ & $<0.0001^{\star}$ \\
\hline School education (years) & $15(3)$ & $15(11-18)$ & $14(3)$ & $14(10-18)$ & $16(2)$ & $16(12-18)$ & $14(3)$ & $14(10-18)$ & $15(3)$ & $16(11-18)$ & $<0.0001^{\star}$ \\
\hline \multirow[t]{2}{*}{$\begin{array}{l}\text { Ejaculation abstinence } \\
\text { (hours)§ }\end{array}$} & $192(315)$ & $115(59-498)$ & 215 (348) & $117(59-686)$ & $151(160)$ & $108(58-354)$ & $227(402)$ & $131(69-684)$ & 167 (293) & $111(59-336)$ & $<0.0001^{\star}$ \\
\hline & & Frequency (\%) & & Frequency (\%) & & Frequency (\%) & & Frequency (\%) & & Frequency (\%) & \\
\hline \multicolumn{12}{|l|}{ Have (had) } \\
\hline Cryptorchidism & & 0.8 & & 0.5 & & 0.8 & & 1.3 & & 0.0 & $0.8^{* *}$ \\
\hline Testicular torsion & & 0.0 & & 0.0 & & 0.0 & & 0.0 & & 0.0 & - \\
\hline Orchitis & & 0.1 & & 0.5 & & 0.0 & & 0.0 & & 0.0 & 0.4 \\
\hline Varicocele & & 0.1 & & 0.0 & & 0.0 & & 0.4 & & 0.0 & 1.0 \\
\hline Inguinal hernia & & 3.1 & & 4.4 & & 2.4 & & 3.9 & & 1.0 & $0.3^{\star \star}$ \\
\hline STD†† & & 5.6 & & 8.3 & & 3.2 & & 5.58 & & 5.8 & $0.2^{\star *}$ \\
\hline $\begin{array}{l}\text { Thyroid disease or } \\
\text { diabetes }\end{array}$ & & 0.8 & & 1.0 & & 0.8 & & 0.43 & & 1.0 & $0.9^{\star *}$ \\
\hline Taken medicine $\ddagger \ddagger$ & & 35.1 & & 18.5 & & 42.0 & & 36.5 & & 48.5 & $<0.0001^{\star *}$ \\
\hline $\begin{array}{l}\text { Caused pregnancy } \\
\text { previously }\end{array}$ & & 45.1 & & 42.7 & & 42.8 & & 51.1 & & 41.8 & $0.2 \mathrm{~B}$ \\
\hline $\begin{array}{l}\text { Investigation because } \\
\text { of infertility }\end{array}$ & & 1.5 & & 0.5 & & 1.6 & & 1.3 & & 3.9 & $0.1 \mathrm{~B}$ \\
\hline $\begin{array}{l}\text { Varicocele diagnosed } \\
\text { in study§§ }\end{array}$ & & 11.8 & & 13.6 & & 8.4 & & 13.7 & & - & $0.110 \mathrm{~B}$ \\
\hline Tobacco smoker & & 52.8 & & 67.0 & & 39.6 & & 55.8 & & 49.5 & $<0.0001 \mathrm{~B}$ \\
\hline $\begin{array}{l}\text { Exposed to tobacco in } \\
\text { utero } 1 \text {. }\end{array}$ & & 3.8 & & 7.8 & & 2.0 & & 2.6 & & 2.9 & $0.018 \mathrm{~B}$ \\
\hline \multicolumn{12}{|c|}{ 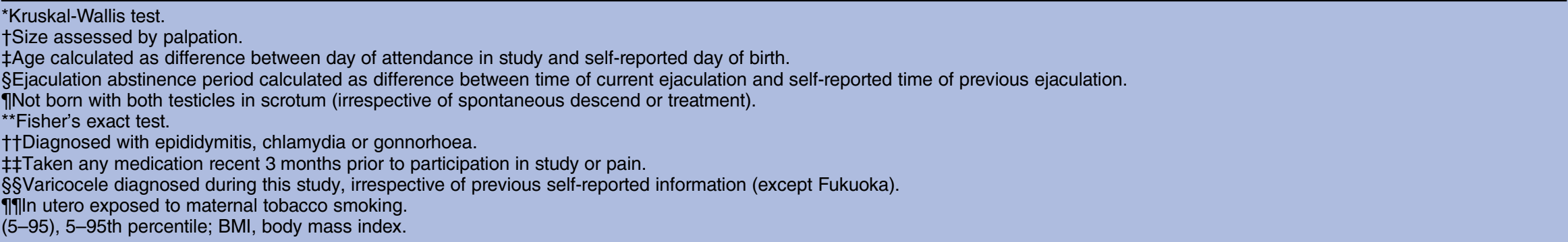 } \\
\hline
\end{tabular}


solution of $0.6 \mathrm{~mol} / 1 \mathrm{NaHCO}_{3}$ and $0.4 \%$ (v/v) formaldehyde in distilled water and subsequently assessed using Bürker-Türk haemocytometers. Only sperm with tails were counted. Smears were prepared for morphological evaluation, Papanicoulaou stained and finally assessed according to strict criteria ${ }^{26}$ by one examiner (MV) in a random and blinded order in Turku, Finland.

\section{Quality control of sperm concentration assessment}

Technicians from each centre were initially trained by one technician from St. Marianna University in Kawasaki. Interlaboratory variation in the assessment of sperm concentration was monitored during the study period by an external quality control programme coordinated by the Department of Growth and Reproduction Copenhagen, Denmark. ${ }^{21} 22$

\section{Blood samples}

A blood sample was drawn from a cubital vein of each participant throughout the daytime, and the serum was separated by centrifugation after clotting and stored at $-20^{\circ} \mathrm{C}$. The frozen serum was sent to the Department of Growth and Reproduction, Rigshospitalet, in Copenhagen, Denmark for a centralised hormone analysis. Levels of testosterone, follicle-stimulating hormone (FSH), luteinising hormone (LH) and sex hormonebinding globulin (SHBG) were determined by using a time-resolved immunofluorometric assay (Delfia, Wallac, Turku, Finland). Inhibin-B was measured by a specific two-sided enzyme immunometric assay (Serotec, UK). Intra-assay and interassay coefficients of variations (CVs) for measurements of both FSH and LH were 3\% and $4.5 \%$, respectively. CVs for both testosterone and SHBG were $<8 \%$ and $<5 \%$, respectively. The intra-assay and interassay CVs for inhibin-B were $15 \%$ and $18 \%$, respectively. We calculated free testosterone (cFT) from total T and SHBG using a fixed albumin level of $43.8 \mathrm{~g} / 1$ as described by Vermeulen $e t a l^{27}$

\section{Statistical analysis}

Standard statistics (mean, median, SD, 5-95 percentiles and frequencies) were used for description (table 1). Between-group differences for continuous variables giving the basic description of the study population were tested by the non-parametric Kruskal-Wallis test. Between-group differences for categorical variables were tested with the Fisher's exact test.

The main outcome variables were the assessed semen and hormone variables, and the between-group differences were tested by multiple-linear regression (tables 2 and 3). Semen volume, sperm concentration and total sperm counts were best normalised by cubic root transformation before analysis to correct for skewed distribution of residuals. The percentages of motile spermatozoa were logit-transformed. Percentages of morphologically normal spermatozoa entered the model untransformed. Ejaculation abstinence up to $96 \mathrm{~h}$ had a linear increasing effect, and abstinence above $96 \mathrm{~h}$, a slight but significant non-linear increasing effect on semen volume, sperm concentrations and total sperm counts. Abstinence, therefore, entered the model as a covariate as linear splines and abstinence-squared for the part above $96 \mathrm{~h}$. For morphology, slight seasonal differences were detected with the highest count in spring and the lowest in autumn. Season was therefore included as a covariate. For all semen variables, increasing age tended to be slightly but negatively associated with semen variables and was also included in the models. Increasing duration from ejaculation to assessment was associated with decreasing motility percentage and included in the statistical model.

Natural logarithmic transformation gave models in which differences between centres and effects of covariates were more easily interpretable. This alternative model closely approximates the model obtained by cubic root transformation and was used when reporting adjusted semen volumes, sperm concentrations and total sperm counts to represent a 32-year-old man having an ejaculation abstinence period of $96 \mathrm{~h}$. QC results did not show any significant intralaboratory difference, changes during the study period or difference to the reference laboratory. Therefore, corrections of data were not needed to make them comparable. The logittransformed motility data and untransformed morphology percentages were used to give adjusted levels for a 32-year-old man for these variables.

Reproductive hormone levels, that is, FSH, inhibin-B, $\mathrm{LH}$, testosterone, SHBG and calculated free-testosterone, were also log-transformed, and the between-group differences were tested by multiple-linear regression adjusted for age, body mass index (BMI), season and blooddrawn time. BMI was entered in linear and quadratic forms, and when reporting the adjusted values, 'a 32-year-old man with a BMI of 23 and blood sampling at $10: 00 \mathrm{~h}$ in winter season' model was represented.

Differences with $\mathrm{p}<0.05$ were considered statistically significant. All statistical analyses were performed twice: MNM using SAS V.9.1.3 (SAS Institute Inc, Cary, North Carolina, USA) and NJ using PASW V.18.

\section{RESULTS}

A description of the study population is summarised in table 1 . Approximately $45 \%$ had previously caused a pregnancy. Few had experienced reproductive health problems. During the preceding 3 months to participation in the study, $35.1 \%$ had used medication. Among these, $63 \%$ did not provide any details of the type of medication. For the remaining, the types were mainly herbal medicine, painkillers or antibiotics.

Table 2 shows semen variables based on the raw data obtained in each city as 'observed' values and the estimates from regression analyses taking covariates into account as 'adjusted' values. Semen volumes, sperm concentrations, percentages of motile spermatozoa and morphologically normal spermatozoa differed between 
Table 2 Semen quality of fertile men from four cities in Japan

\begin{tabular}{|c|c|c|c|}
\hline & \multicolumn{2}{|l|}{ Observed } & \multirow{2}{*}{$\begin{array}{l}\text { Adjusted } \\
\text { Median }(95 \% \mathrm{Cl})\end{array}$} \\
\hline & Mean (SD) & Median (5-95) & \\
\hline \multicolumn{4}{|l|}{ Semen volume (ml) } \\
\hline Entire study population & $3.1(1.5)$ & $3.0(1.0-6.0)$ & 3.0 (2.9 to 3.2$)$ \\
\hline Sapporo & $3.2(1.6)$ & $3.0(1.0-6.1)$ & 2.9 (2.7 to 3.1$)$ \\
\hline Osaka & $2.9(1.5)$ & $2.6(1.0-5.2)$ & 2.7 (2.5 to 3.0$)$ \\
\hline Kanazawa & $3.5(1.6)$ & $3.2(1.4-6.0)$ & 3.2 (3.0 to 3.4 ) \\
\hline Fukuoka & $2.8(1.4)$ & $2.6(1.0-5.2)$ & 2.7 (2.5 to 3.0$)$ \\
\hline p Value & & & 0.006 \\
\hline \multicolumn{4}{|c|}{ Sperm concentration (mill/ml) } \\
\hline Entire study population & $105(83)$ & $84(18-257)$ & 84 (76 to 92 ) \\
\hline Sapporo & $110(84)$ & $95(22-244)$ & 89 (76 to 104$)$ \\
\hline Osaka & 97 (79) & $76(15-253)$ & 80 (70 to 93$)$ \\
\hline Kanazawa & $105(76)$ & $84(17-259)$ & 80 (70 to 92$)$ \\
\hline Fukuoka & $115(102)$ & $89(21-263)$ & 98 (80 to 120$)$ \\
\hline p Value & & & 0.04 \\
\hline \multicolumn{4}{|l|}{ Total sperm count (mill) } \\
\hline Entire study population & $317(294)$ & $239(38-818)$ & 255 (230 to 282 ) \\
\hline Sapporo & $331(300)$ & $255(44-800)$ & 264 (223 to 312$)$ \\
\hline Osaka & 266 (239) & $198(26-712)$ & 222 (195 to 267$)$ \\
\hline Kanazawa & $357(307)$ & $284(50-848)$ & 266 (228 to 309$)$ \\
\hline Fukuoka & $324(350)$ & $229(48-1007)$ & 276 (221 to 346$)$ \\
\hline p Value & & & 0.07 \\
\hline \multicolumn{4}{|l|}{ Motile spermatozoa (\%) } \\
\hline Entire study population & $67(21)$ & $66(31-100)$ & 77 (74 to 79$)$ \\
\hline Sapporo & $62(18)$ & $65(28-87)$ & 66 (61 to 70$)$ \\
\hline Osaka & 85 (19) & $92(46-100)$ & 94 (93 to 95$)$ \\
\hline Kanazawa & $55(15)$ & $56(30-77)$ & 60 (48 to 56$)$ \\
\hline Fukuoka & $60(14)$ & $60(34-82)$ & 69 (62 to 74$)$ \\
\hline p Value & & & $<0.0001$ \\
\hline \multicolumn{4}{|c|}{ Morphologically normal spermatozoa $(\%)^{*}$} \\
\hline Entire study population & $9.8(6.1)$ & $8.5(1.5-21.5)$ & 9.3 (8.4 to 10.3$)$ \\
\hline Sapporo & & & \\
\hline Osaka & $8.6(5.2)$ & $8(1.0-1.08 .5)$ & 8.4 (7.3 to 9.6$)$ \\
\hline Kanazawa & $11.8(6.9)$ & $10.5(2.0-24.5)$ & $11.3(10.2$ to 12.4$)$ \\
\hline Fukuoka & $8.1(5.1)$ & $7.0(1.5-18.0)$ & 7.7 (6.4 to 9.0$)$ \\
\hline $\mathrm{p}$ Value & & & $<0.0001$ \\
\hline \multicolumn{4}{|c|}{ 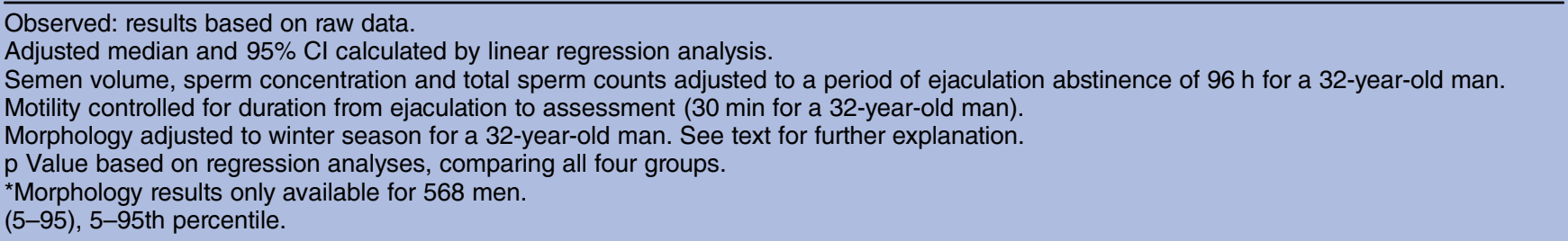 } \\
\hline
\end{tabular}

the four groups, whereas no differences in total sperm counts were found. In total, $1.2 \%$ of men had a sperm concentration below 5 million $/ \mathrm{ml}, 2.1 \%$ below 10 million/ml, $3.5 \%$ below 15 million/ml and $16.3 \%$ below 40 million/ml. For morphology, $14.7 \%$ had less than $5 \%$ and $10.4 \%$ less than $4 \%^{28}$ normal spermatozoa. Reproductive hormone levels differed between the groups except for FSH (table 3). Inhibin-B levels varied with the highest values in Osaka and the lowest in Kanazawa. The adjusted values for $\mathrm{LH}$, testosterone and cFT were highest for the men from Kanazawa.

The semen variables of men whose mothers had smoked during pregnancy did not significantly differ from those of non-exposed men, but the number of smoking mothers was very small $(3.8 \%)$, disallowing robust statistical evaluation. The men's own smoking habits did not affect the sperm counts. A previous diagnosis of sexually transmitted disease or recent medication (table 1) did not affect sperm counts. Men who had previously caused a pregnancy were older (32.8 vs 30.6 years, $\mathrm{p}<0.0001)$ and had a higher sperm concentration (89 vs $82 \mathrm{mill} / \mathrm{ml}, \mathrm{p}=0.01$ ) than those who had caused a pregnancy for the first time.

In men who were diagnosed during the study as having a varicocele, the sperm concentration was $29 \%$ $(95 \%$ CI $9 \%$ to $37 \%)$ lower than in others. Similarly, 
Table 3 Reproductive hormone levels of fertile men from four cities in Japan

\begin{tabular}{|c|c|c|c|}
\hline & \multicolumn{2}{|l|}{ Observed } & \multirow{2}{*}{$\begin{array}{l}\text { Adjusted } \\
\text { Median }(95 \% \mathrm{Cl})\end{array}$} \\
\hline & Mean (SD) & Median (5-95) & \\
\hline \multicolumn{4}{|l|}{$\mathrm{FSH}(\mathrm{U} / \mathrm{l})$} \\
\hline Entire study population & $4.1(2.4)$ & $3.6(1.8-7.8)$ & 3.9 (3.6 to 4.2$)$ \\
\hline Sapporo & $4.3(2.4)$ & $3.7(1.7-8.6)$ & 4.2 (3.8 to 4.6$)$ \\
\hline Osaka & $4.1(2.8)$ & $3.7(1.8-7.7)$ & 3.8 (3.5 to 4.2$)$ \\
\hline Kanazawa & $4.1(2.1)$ & $3.5(1.8-7.7)$ & 4.0 (3.7 to 4.4$)$ \\
\hline Fukuoka & $4.0(2.0)$ & $3.6(2.0-7.0)$ & 3.7 (3.4 to 4.1$)$ \\
\hline p Value & & & 0.2 \\
\hline \multicolumn{4}{|l|}{ Inhibin-B (pg/ml) } \\
\hline Entire study population & $178(56)$ & $173(94-279)$ & $176(167$ to 186$)$ \\
\hline Sapporo & $182(56)$ & 179 (104-278) & $179(167$ to 194$)$ \\
\hline Osaka & $190(59)$ & 187.5 (104-297) & $188(176$ to 201$)$ \\
\hline Kanazawa & $161(52)$ & $162(83-260)$ & $158(147$ to 170$)$ \\
\hline Fukuoka & $180(50)$ & 169 (117-279) & 178 (165 to 192$)$ \\
\hline $\mathrm{p}$ Value & & & $<0.0001$ \\
\hline \multicolumn{4}{|l|}{$\mathrm{LH}(\mathrm{U} / \mathrm{l})$} \\
\hline Entire study population & $3.7(1.5)$ & $3.5(1.9-6.4)$ & 3.3 (3.1 to 3.5$)$ \\
\hline Sapporo & $3.8(1.6)$ & $3.4(1.9-6.3)$ & 3.5 (3.2 to 3.8$)$ \\
\hline Osaka & $3.5(1.4)$ & $3.3(1.8-5.6)$ & 3.2 (3.0 to 3.5$)$ \\
\hline Kanazawa & $4.0(1.6)$ & $3.8(2-7.1)$ & 3.7 (3.4 to 4.0$)$ \\
\hline Fukuoka & $3.4(1.4)$ & $3.2(1.7-6.1)$ & 3.1 (2.9 to 3.4$)$ \\
\hline p Value & & & 0.0002 \\
\hline \multicolumn{4}{|l|}{ Testosterone (nmol/l) } \\
\hline Entire study population & $20(7)$ & $18(11-31)$ & 19 (18 to 20$)$ \\
\hline Sapporo & $19(6)$ & $18(10-31)$ & 18 (17 to 20$)$ \\
\hline Osaka & $19(6)$ & $18(12-28)$ & 19 (18 to 20$)$ \\
\hline Kanazawa & $22(7)$ & $21(12-33)$ & 21 (20 to 23 ) \\
\hline Fukuoka & $19(8)$ & $17(10-30)$ & 18 (17 to 19$)$ \\
\hline p Value & & & $<0.0001$ \\
\hline \multicolumn{4}{|l|}{ SHBG (nmol/l) } \\
\hline Entire study population & $33(15)$ & $31(16-56)$ & 31 (30 to 33$)$ \\
\hline Sapporo & $34(14)$ & $33(16-58)$ & 34 (31 to 36$)$ \\
\hline Osaka & $33(15)$ & $31(17-56)$ & 33 (30 to 35$)$ \\
\hline Kanazawa & $34(15)$ & $31(16-56)$ & 33 (30 to 35$)$ \\
\hline Fukuoka & $30(15)$ & $27(15-52)$ & 29 (27 to 31$)$ \\
\hline $\mathrm{p}$ Value & & & 0.02 \\
\hline \multicolumn{4}{|l|}{$\mathrm{cFT}(\mathrm{pmol} / \mathrm{l})$} \\
\hline Entire study population & $416(143)$ & 392 (251-642) & 400 (382 to 419$)$ \\
\hline Sapporo & $384(113)$ & $363(238-625)$ & 376 (354 to 399$)$ \\
\hline Osaka & $400(123)$ & $381(255-591$ & 399 (377 to 421 \\
\hline Kanazawa & $464(154)$ & 440 (268-677) & 448 (422 to 476$)$ \\
\hline Fukuoka & $410(183)$ & $392(240-614$ & 395 (372 to 420$)$ \\
\hline p Value & & & $<0.0001$ \\
\hline
\end{tabular}

Observed: results based on raw data.

Adjusted median and $95 \% \mathrm{Cl}$ calculated by linear regression analysis, adjusted to blood sampling at 10:00 $\mathrm{h}$ in winter season, representing of 32-year-old man having a BMI of 23.

$\mathrm{p}$ Value based on regression analyses of natural logarithmic transformed values comparing all four groups.

(5-95): 5-95th percentile; BMI, body mass index; CFT, calculated free-testosterone; FSH, follicle-stimulating hormone; LH, luteinising hormone; SHBG, sex hormone-binding globulin.

there was a reduction in total sperm counts of $30 \%$ $(9 \%$ to $46 \%)$ and in percentages of motile spermatozoa of $40 \%(10 \%$ to $60 \%)$. Serum levels of FSH, inhibin-B and testosterone did not differ from others. For the remaining male reproductive health problems listed in table 1 , the numbers were too small to allow for a valid statistical evaluation. Overall, $97.6 \%$ of study subjects had a pubic hair distribution of Tanner stage 4 or higher: Sapporo 98.1\%, Osaka 96.4\%, Kanazawa $100 \%$ and Fukuoka 94.2\%.

\section{DISCUSSION}

This is the first large cross-sectional study on semen quality of fertile men from major regions of Japan including Sapporo, Osaka, Kanazawa and Fukuoka. We 
detected only minor differences in their semen quality, which was generally higher than that seen in a previous study of men from Kawasaki located in the Tokyo metropolitan area in Japan. ${ }^{24}$ This suggests that the metropolitan area may differ from the rest of the country with regard to semen quality. Overall, these Japanese semen quality data are similar to those reported from European countries, including Finland and Denmark. ${ }^{21}$

WHO published the latest guidelines and reference values of semen analysis in $2010 .{ }^{28}$ These are based on several prospective cross-sectional studies of fertile men whose partner conceived within 12 months after stopping contraception. However, the background publications did not all request conception within 12 months, for example, our own, ${ }^{21}$ but data on time to pregnancy were available. ${ }^{29}$ The new reference values define the fifth percentile of the fertile men, and those are now clearly lower than the previous values. ${ }^{25}$ Interestingly, the present Japanese semen values are close to the WHO reference values, and the fifth percentiles for sperm concentration and total sperm count are 18 million/ml (WHO reference 15 million/ml) and 38 million (WHO reference 39 million), respectively.

Comparisons between semen quality studies can be limited by many confounders such as population characteristics and methodological differences in semen analysis. To avoid technical and study design differences, this study was designed in the same way as the previously published Japanese study of fertile men ${ }^{24}$ that was conducted on the basis of the European study of fertile men, ${ }^{21}$ and we shared the protocols and the external quality control programme with these studies. Male partners of pregnant women were chosen for the international comparative studies, because they constituted a well-defined group. The participation rate in this study was higher than in a similar US study ${ }^{12}$ and at an intermediate level as compared with those in the European study. ${ }^{21}$ Despite common protocols and the external quality control of semen analyses, some differences remained in the procedures, which may have influenced the results. Semen volume was assessed with the aspiration method in the present study, whereas in many other studies, for example, the European studies on fertile men, ${ }^{21}$ weighing of the whole sample was used. This may have led to approximately $0.4 \mathrm{ml}$ underestimation of the true volume. ${ }^{30} 31$ If those corrections were made, the current volume measures would be close to the European levels, and consequently the total sperm counts would be even higher than presented. In Kanazawa, median semen volume was higher than in other cities, which may have resulted from interobserver variation. The external quality control programme registered only possible differences in sperm concentrations but not in the assessment of testicular volume, semen volume or sperm motility. Therefore, the high motility measure of $94 \%$ from Osaka may also be due to laboratory variation, while the percentage of motile sperm in all other centres was rather similar to each other
(52-69\%). Levels of reproductive hormones varied between centres, and the reasons for this are not currently known. We could not standardise the sampling time to morning, because most of the study subjects were employed in full-time jobs, and therefore blood samples were taken throughout the day. We tried to account for this by adjusting for hour of blood sampling in the statistical analyses, similar to how it has been done in other studies. ${ }^{12} 2122243233$

Influence of ethnicity and genetic background on semen quality is poorly known. Lower testis parenchymal weight, ${ }^{34}$ lower androsterone glucuronide levels despite similar serum testosterone levels, ${ }^{35}{ }^{36}$ lower testosterone production rate ${ }^{37}$ and longer CAG repeats in the androgen receptor gene ${ }^{38}$ have been reported in Asian men compared with Hispanic or non-Hispanic white men. Chia et $a l^{39}$ reported low sperm counts in the Chinese, Malaysians and Indians living in Singapore, indicating large variations among Asian men. Zhang $e t a t^{t}$ analysed the trend of mean sperm concentration in Chinese fertile men from 1983 to 1996. According to the English abstract, semen data were collected from 114 published papers (mostly written in Chinese) including 256 datasets from 9292 men and 11726 semen assays from 39 cities. The mean sperm concentration decreased from 103 million/ml in 1983 to 84 million $/ \mathrm{ml}$ in 1996 . Although the semen quality of fertile men in China was good as compared with reports from many other countries for the same period, the speed of decline was remarkably high.

Assessment of testicular size with a Prader orchidometer is somewhat subjective and prone to large interobserver variation. Ethnic differences in testis size, that is, smaller in Asian men than in Caucasians, have been reported in some studies. ${ }^{40-42}$ The mean testicular volumes of Korean normal men, ${ }^{43}$ Chinese fertile men, ${ }^{44}$ Thai fertile men $^{45}$ and Chinese normal men ${ }^{44}$ were 19.4, 17.7, 17.2 and $17 \mathrm{ml}$, respectively. These values are lower than those reported from Europe where the mean testicular volumes in fertile men from four European cities were $23.5 \mathrm{ml}$ (Copenhagen, Denmark), $23 \mathrm{ml}$ (Edinburgh, Scotland), $22.5 \mathrm{ml}$ (Paris, France) and $23 \mathrm{ml}$ (Turku, Finland). In the previously published study of fertile Japanese from Kawasaki, the mean testicular volume was $21.5 \mathrm{ml},{ }^{24}$ and in the current study the mean volumes ranged from 19.3 to $20.9 \mathrm{ml}$. This seems to indicate that that Japanese men may have somewhat larger testes than other Asian men but smaller than those of Europeans. However, without strict standardisation and analysis of interobserver variation, the figures are difficult to compare and may not present true differences.

Taken together, the study results show that semen quality of fertile Japanese men from four different regions is comparable to that in the best European regions. The reasons for global differences are not known, but both genetic and environmental factors possibly play roles. A close survey of semen quality over time 
seems warranted to observe possible temporal or regional trends. Our results may also serve as reference values for studies of men from the general population.

\section{Author affiliations}

${ }^{1}$ Department of Urology, St Marianna University School of Medicine, Kawasaki, Japan

${ }^{2}$ Division of Male Infertility, Centre for Infertility and IVF, International University of Health and Welfare Hospital, Nasushiobara, Japan

${ }^{3}$ Department of Urology, Kanazawa University Graduate School of Medical Sciences, Kanazawa, Japan

${ }^{4}$ Department of Urology, Graduate School of Medicine, Faculty of Medicine, Osaka University, Osaka, Japan

${ }^{5}$ Department of Urology, Harasanshinkai Hospital, Fukuoka, Japan

${ }^{6}$ Department of Urology, Sapporo Medical University, Sapporo, Japan

${ }^{7}$ Department of Medical Informatics, Centre for Information, Jichi Medical University, Shimotsuke, Japan

${ }^{8}$ Departments of Physiology and Paediatrics, University of Turku, Turku, Finland

${ }^{9}$ University Department of Growth and Reproduction, Rigshospitalet, University of Copenhagen, Copenhagen, Denmark

Acknowledgements Dr K Nishimura, Dr H Miura and Dr M Yamanaka are acknowledged for performing a physical examination of the fertile men. Ms Y Kawabuchi and Mr K Abe are acknowledged for examination of semen quality. All the study nurses and technicians of the four centres are acknowledged for coordinating the recruitment and for examination of semen quality. All the volunteers participating in the study are thanked. Without their participation, the study would not have been possible.

Contributors TI, SN, MY, MNM, NES, JT and NJ made substantial contributions to the conception and design. TI, MY, SN, MN, EK, JK, AO, KM, AT, TT, NI, KK and MV were involved in acquisition of data. TI, SN, MNM, NES, JT and NJ were involved in analysis of data. All authors were involved in interpretation of data. TI, SN, MNM, NES, JT and NJ were involved in the drafting of the article. All authors were involved in a critical revision of the article for important intellectual content. All authors participated in the final approval of the version to be published.

Funding This study has been supported economically by several grants: The Ministry of Health and Welfare, Japan (Grant nos. H10-Seikatsu-017 and H13-Seikatsu-014 to TI, A0, MN, TT and KK). Japan Society for the Promotion of Science (nos. 1113001 and 1214001 to TI) and The JSPS Invitation Fellowship Programme (invited a scientist from Denmark, NJ) by Japan Society for the Promotion of Science (ID no. S10110), Rigshospitalet (Grant no. 961506336) to NJ, Academy of Finland, Sigrid Juselius Foundation and Turku University Hospital to JT. The funding organisations played no role in the design and conduct of the study, in collection, management, analysis and interpretation of the data; or in the presentation, review or approval of the manuscript.

Competing interests None.

Ethics approval This study got the approval of the Ethics Review Board in each university and hospital. All participants gave their written consent before participating in the study.

Provenance and peer review Not commissioned; externally peer reviewed.

Data sharing Statement No additional data are available.

\section{REFERENCES}

1. Carlsen E, Giwercman A, Keiding N, et al. Evidence for decreasing quality of semen during past 50 years. BMJ 1992;305:609-13.

2. Van Waeleghem $\mathrm{K}$, De Clercq N, Vermeulen L, et al. Deterioration of sperm quality in young healthy Belgian men. Hum Reprod 1996;11:325-9.

3. Younglai EV, Collins JA, Foster WG. Canadian semen quality: an analysis of sperm density among eleven academic fertility centers. Fertil Steril 1998;70:76-80.
4. Zhang SC, Wang HY, Wang JD. Analysis of change in sperm quality of Chinese fertile men during 1981-1996. Reprod Contracept 1999;10:33-9.

5. Horte A, Vierula M, Toppari J, et al. Reassessment of sperm morphology of archival semen smears from the period 1980-94. Int $J$ Androl 2001;24:120-4.

6. Auger J, Kunstmann JM, Czyglik F, et al. Decline in semen quality among fertile men in Paris during the past 20 years. N Engl $J$ Med 1995;332:281-55.

7. Adamopoulos DA, Pappa A, Nicopoulou S, et al. Seminal volume and total sperm number trends in men attending subfertility clinics in the greater Athens area during the period 1977-1993. Hum Reprod 1996;11:1936-41.

8. Bilotta $P$, Guglielmo R, Steffe M.,, et al Analysis of decline in seminal fluid in the Italian population during the past 15 years. Minerva Gineco 1999;51:223-31.

9. Bendvold E. Semen quality in Norwegian men over a 20 -year period. Int J Fertl 1989;34:401-4.

10. Irvine RA, Cawood E, Richardson D, et al. Evidence of deteriorating semen quality in the United Kingdom: birth cohort study in 577 men in Scotland over 11 years. BMJ 1996;24:467-71.

11. Leto S, Frensilli FJ. Changing parameters of donor semen. Fertil Steril 1981;36:766-70.

12. Swan SH, Brazil C, Drobinis EZ, et al. Geographic differences in semen quality of fertile US males. Environ Health Perspect 2003;111:414-20.

13. Ginsburg J, Okolo S, Prelevic G, et al. Residence in the London area and sperm density. Lancet 1994;343:230.

14. Zhu X, Shen $\mathrm{Y}$, Zhang $\mathrm{X}$, et al. Trend analysis of sperm quality during the past 13 years in China. $J$ Zhejiang Univ (Med Edn) 2000;29:173-5.

15. Rasmussen PE, Erb K, Westergaard LG, et al. No evidence for decreasing semen quality in four birth cohorts of 1,055 Danish men born between 1950 and 1970. Fertil Steril 1997;68:1059-64.

16. Suominen J, Vierula M. Semen quality of Finnish men. BMJ 1993:306:1579.

17. Vierula M, Niemi M, Keiski A, et al. High and unchanged sperm counts of Finnish men. Int $J$ Androl 1996;19:11-17.

18. Bujan L, Mansat A, Pontonnier F, et al. Time series analysis of sperm concentration in fertile men in Toulouse, France between 1977 and 1992. BMJ 1996;312:471-2.

19. Benshushan A, Shoshani O, Paltiel O, et al. Is there really a decrease in sperm parameters among healthy young men? A survey of sperm donations during 15 years. J Assist Reprod Genet 1997;14:347-53.

20. Fisch H, Goluboff E, Olson J, et al. Semen analyses in 1283 men from the United States over a 25-year period: No decline in quality. Fert Steril 1996;65:1009-14.

21. Jørgensen N, Andersen AG, Eustache F, et al. Regional differences in semen quality in Europe. Hum Reprod 2001;16:1012-19.

22. Jørgensen N, Carlsen E, Nermoen I, et al. East-West gradient in semen quality in the Nordic-Baltic area: a study of men from the general population in Denmark, Norway, Estonia and Finland. Hum Reprod 2002;17:2199-208.

23. Jørgensen N, Vierula M, Jacobsen R, et al. Recent adverse trends in semen quality and testis cancer incidence among Finnish men. Int $J$ Androl 2011;34:e37-48.

24. Iwamoto T, Nozawa S, Yoshiike M, et al. Semen quality of 324 fertile Japanese men. Hum Reprod 2006;21:760-5.

25. World Health Organisation. WHO laboratory manual for the examination of human semen and sperm-cervical mucus interaction, 3rd edn. Cambridge: Cambridge University Press, 1992.

26. Menkveld R, Stander FS, Kotze TJ, et al. The evaluation of morphological characteristics of human spermatozoa according to stricter criteria. Hum Reprod 1990;5:586-92

27. Vermeulen A, Verdonck L, Kaufman JM. A critical evaluation of simple methods for the estimation of free testosterone in serum. $J$ Clin Endocrinol Metab 1999;84:3666-72.

28. World Health Organization. WHO laboratory manual for the examination and processing of human Semen, 5th edn. Geneva: WHO Press, 2010.

29. Cooper TG, Noonan E, von Eckardstein S, et al. World Health Organization reference values for human semen characteristics. Hum Reprod Update. 2010;6:231-45.

30. Jørgensen N, Auger J, Giwercman A, et al. Semen analysis performed by different laboratory teams: an intervariation study. Int $J$ Androl 1997:20:201-8.

31. Cooper TG, Brazil C, Swan SH, et al. Ejaculate volume is seriously underestimated when semen is pipetted or decanted into cylinders from the collection vessel. J Andro/ 2007;28:1-4. 
32. Paasch U, Salzbrunn A, Glander HJ, et al. Semen quality in sub-fertile range for a significant proportion of young men from the general German population: a co-ordinated, controlled study of 791 men from Hamburg and Leipzig. Int J Androl 2008;31:93-102.

33. Fernandez MF, Duran I, Olea N, et al. Semen quality and reproductive hormone levels in men from Southern Spain. Int $J$ Androl 2012;35:1-10.

34. Johnson L, Barnard JJ, Rodriguez L, et al. Ethnic differences in testicular structure and spermatogenic potential may predispose testes of Asian men to a heightened sensitivity to steroidal contraceptives. J Androl 1998;19:348-57.

35. Lookingbill DP, Demers LM, Wang C, et al. Clinical and biochemical parameters of androgen action in normal healthy Caucasian versus Chinese subjects. J Clin Endocrinol Metab 1991;72:1242-8.

36. Ross RK, Bernstein L, Lobo RA, et al. 5-Alpha-reductase activity and risk of prostate cancer among Japanese and US white and black males. Lancet 1992;339:887-9.

37. Santner SJ, Albertson B, Zhang GY, et al. Comparative rates of androgen production and metabolism in Caucasian and Chinese subjects. J Clin Endocrinol Metab 1998;83:2104-9.
38. Irvine RA, Yu MC, Ross RK, et al. The CAG and GGC microsatellites of the androgen receptor gene are in linkage disequilibrium in men with prostate cancer. Cancer Res 1995:55:1937-40.

39. Chia SE, Tay SK, Lim ST, et al. What constitutes a normal semina analysis? Semen parameters of 243 fertile men. Hum Reprod 1998;13:3394-8.

40. Diamond JM. Variation in human testis size. Nature 1986;320:488-9.

41. Mittwoch U. Ethnic differences in testis size: a possible link with the cytogenetics of true hermaphroditism. Hum Reprod 1988;3:445-9.

42. Iwamoto T, Nozawa S, Yoshiike M. Semen quality of Asian men. Reprod Med Biol 2007;6:185-93.

43. Kim DH, Lee HY. Clinical investigation of testicular size. I. Testis size of normal Korean male. J Korean Med Ass 1982;25:135.

44. Wang C, Chan SYW, Leung A.,, et al Cross-sectional study of semen parameters in a large group of normal Chinese men. Int $J$ Androl 1985;8:257-74.

45. Aribarg A, Kenkeerati W, Vorapaiboonsak V, et al. Testicular volume semen profile and serum hormone levels in fertile Thai males. Int $J$ Androl 1986;9:170-80. 